\section{Dosage-sensitive requirement for mouse Dll4 in artery development}

\author{
António Duarte, ${ }^{1,5}$ Masanori Hirashima, ${ }^{3,5,6}$ \\ Rui Benedito, ${ }^{1}$ Alexandre Trindade, ${ }^{1}$ \\ Patrícia Diniz, ${ }^{1}$ Evguenia Bekman, ${ }^{2}$ Luís Costa, ${ }^{1}$ \\ Domingos Henrique, ${ }^{2}$ and Janet Rossant ${ }^{3,4,7}$
}

${ }^{1}$ CIISA, Faculdade de Medicina Veterinária, 1300-0-477 Lisboa, Portugal; ${ }^{2}$ Instituto de Medicina Molecular, Faculdade de Medicina, 1649-9-028 Lisboa, Portugal; ${ }^{3}$ Samuel Lunenfeld Research Institute, Mount Sinai Hospital, Toronto, Ontario, Canada M5G1X5; ${ }^{4}$ Department of Molecular and Medical Genetics, University of Toronto, Toronto, Ontario, Canada M5S 1A8

Involvement of the Notch signaling pathway in vascular development has been demonstrated by both gain- and loss-of-function mutations in humans, mice, and zebrafish. In zebrafish, Notch signaling is required for arterial identity by suppressing the venous fate in developing artery cells. In mice, the Notch 4 receptor and the Delta-like 4 (D114) ligand are specifically expressed in arterial endothelial cells, suggesting a similar role. Here we show that the Dll4 ligand alone is required in a dosage-sensitive manner for normal arterial patterning in development. This implicates D114 as the specific mammalian endothelial ligand for autocrine endothelial Notch signaling, and suggests that D114 may be a suitable target for intervention in arterial angiogenesis.

Received July 12, 2004; revised version accepted August 19, 2004.

\section{Results and Discussion}

Gain- and loss-of-function mutations in humans, mice, and zebrafish have demonstrated the importance of Notch signaling in the regulation of vascular development (Shawber and Kitajewski 2004). In zebrafish, Notch signaling is required for arterial identity by suppressing the venous fate in developing artery cells (Zhong et al. 2001; Lawson et al. 2002). In mice, the Notch4 receptor (Villa et al. 2001) and the Delta-like 4 (D1l4) ligand (Shutter et al. 2000; Mailhos et al. 2001; Villa et al. 2001) are specifically expressed in arterial and not venous endothelial cells, suggesting a possible similar role. Knockout of the Notch4 receptor gave no obvious phenotype alone, although Notch1/Notch4 double mutant embryos did show severe vascular remodeling defects (Krebs et al.

[Keywords: Angiogenesis; Dll4; Notch; haploinsufficiency; dosage sensitivity; arteriogenesis]

${ }^{5}$ These authors contributed equally to this work.

${ }^{6}$ Present address: Department of Cell Differentiation, The Sakaguchi Laboratory, School of Medicine, Keio University, 35 Shinano-machi, Shinjuku-ku, Tokyo, 160-0-8582, Japan.

${ }^{7}$ Corresponding author.

E-MAIL: rossant@mshri.on.ca; FAX (416) 586-8588.

Article published online ahead of print. Article and publication date are at http://www.genesdev.org/cgi/doi/10.1101/gad.1239004.
2000), which were also observed, to a lesser degree, in Hey1/Hey2 double mutants, the putative downstream targets of Notch signaling (Fischer et al. 2004). Here we show, in contrast, that the Dll4 ligand alone is required in a dosage-sensitive manner for normal arterial patterning in development.

The $D 114$ gene was inactivated by targeted disruption in embryonic stem (ES) cells. The targeting vector was designed to replace the initiation codon and the first three coding exons with the $\beta$-galactosidase (lacZ) reporter gene (Fig. 1A). Electroporation of R1 ES cells with the targeting vector followed by G418 selection resulted in the derivation of four correctly gene-targeted ES cell lines. Chimeric mice were generated by aggregation between $D 114^{+/-}$ES cells and ICR host embryos. When crossed with wild-type ICR females, five male chimeras produced F1 agouti pups at 100\% frequency. Genotyping of F1 agouti mice by Southern blotting or polymerase chain reaction $(\mathrm{PCR}$; Fig. $1 \mathrm{~B}, \mathrm{C})$ identified $\mathrm{D}_{114^{+}-}$individuals at only $21 \%$ frequency (55 out of 260 ), suggesting the death in utero of a proportion of the $D 114^{+/-} \mathrm{F} 1 \mathrm{em}-$ bryos. Outcrossing these viable heterozygotes to ICR mice still resulted in a reduced number of heterozygotes in subsequent generations. This effect was dependent on the genetic background, as no live $D 114^{+/-}$offspring were obtained when the $100 \%$ germ-line transmitter chimeric males were crossed with $129 /$ Sv-CP females $(n=65)$.

To further characterize this incompletely penetrant haploinsufficiency, the phenotypes of $D 114^{+/-}$embryos were investigated. Two different approaches were used to obtain heterozygous embryos: F1 embryos from ICR females crossed with $100 \%$ germ-line transmitting chimeric males $(n=52)$ and $D 114^{+/-}$ES-derived embryos $(n=59)$ generated by aggregation between $D 114^{+/-}$ES cells (from two different independent cell lines) and $D 114^{+/+}$, EGFP-labeled tetraploid host embryos. The EGFP reporter was used to confirm the absence of tetraploid cells in the embryo proper of chimeric embryos. $D 114^{+/-}$embryos obtained by either approach displayed similar phenotypic traits.

The $D 114^{+/-}$embryos were dissected at embryonic day 7.5-10.5 (E7.5-E10.5) and stained with X-gal or immunostained for PECAM. In pre-somite stages, lacZ expression was exclusively detected in trophoblast giant cells (data not shown). Around the two-somite stage (E8.0), the lac $Z$ reporter was expressed in the cardiac crescent and the primordia of the dorsal aortae (Fig. 2A). At the five- to 10-somite stage (E8.5), it was expressed in the heart, paired dorsal aortae, branchial arch arteries, internal carotid arteries, umbilical artery, vitelline artery, and in the posterior region of the yolk sac where the arteries are formed (Fig. 2B,C). This expression pattern is consistent with previous reports that Dll4 is an early marker for arterial endothelial cells (Shutter et al. 2000; Mailhos et al. 2001; Villa et al. 2001).

At E8.5 there were no obvious differences between wild-type and D114+/- embryos (data not shown). As development proceeded, however, some heterozygous embryos started to show developmental delay. At E9.5 only $31 \%$ of the $D 114^{+/-}$embryos $(n=32)$ were normal in body size and somite number (mean somite number \pm S.D.: $22.0 \pm 1.5 ; n=10)$, and the rest showed growth retardation (mean somite number $19.5 \pm 1 ; n=22$ ) compared 

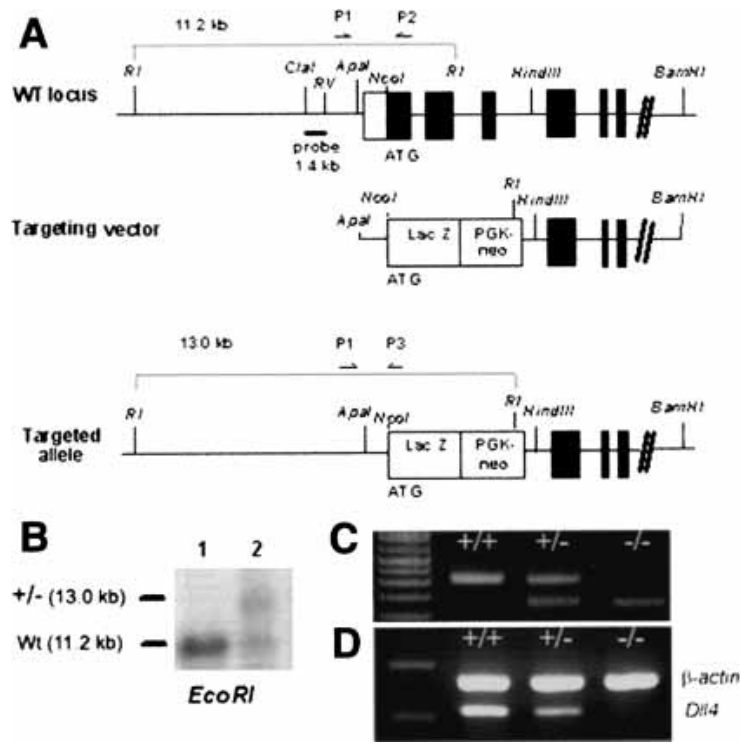

Figure 1. Generation of Dll4 mutant mice. (A) Schematic representations of the wild-type Dll4 locus, targeting vector, and mutant allele. The probe for Southern blot analysis (ClaI-EcoRV genomic fragment) and the PCR primers (P1-P3) used for genotyping are indicated. (B) Southern blot analysis of control (lane 1) and targeted (lane 2) ES cells. Genomic DNA was digested with EcoRI and hybridized with the ClaI-EcoRV probe. (C) PCR genotyping of wildtype $(+/+)$, heterozygous $(+/-)$, and Dll4 homozygous null $(-/-)$ mice with primers $\mathrm{P} 1, \mathrm{P} 2$, and P3. (D) RT-PCR analysis of D114 gene expression in E9.5 wild-type $(+/+)$, heterozygous $(+/-)$, and double mutant embryos $(-/-)$.

with the wild-type littermates. At E10.5, two types of $D 114^{+/-}$conceptuses $(n=34)$ were found: normal-sized embryos with reduced vitelline circulation $(n=11)$, and severely retarded embryos with reduced vitelline circulation and enlarged pericardial space, indicative of embryonic circulatory defects (Fig. 2D-F; $n=23$ ). The caliber of the major vitelline arteries and the arterial branching on the yolk sac was reduced in all of the heterozygous embryos (Fig. 2I,J). The umbilical artery and placental blood vessels were also reduced in size in some $D 114^{+/-}$embryos (Fig. 2G,H). The dependence of the embryo on the vitelline circulation for gas and nutrient exchange is only transient until the placental circulation is established. The variable phenotype of the placental vascular bed probably explains why some $D 114^{+/-}$embryos could survive to term, despite the poor vitelline circulation in all heterozygotes.

Defects in vascular structures were also seen within the $D 114^{+/-}$embryos, most notably the reduction of the caliber of the dorsal aortae. At E9.0 the dorsal aortae were already thinner than normal in $60 \%$ of the embryos $(n=15)$, a feature which was accentuated at E9.5 $(n=32)$ and E10.5 $(n=34)$. The constriction of the dorsal aortae was primarily observed rostrally between the cardiac level and the intersections with the branchial arch arteries (Fig. 2K-P), but some embryos exhibited longer zones of constriction extending caudally (data not shown). At both E9.5 and E10.5 ( $n=66), 90 \%$ of the embryos displayed some degree of aortic constriction. The degree of constriction was variable among embryos and also between the dorsal aortae of any specific embryo. Interestingly, when the aortic lesions were asymmetric (observed in $50 \%$ of the embryos), the left dorsal aorta was always more severely affected. The potential impact of these arterial defects on the development of the venous system was also investigated. Reduced caliber and disorganization of the anterior and posterior cardinal veins were observed in the $D 114^{+/-}$embryos, but only in those cases where the dorsal aortae were severely affected, suggesting that the venous defect is a secondary response to a primary arterial restriction (Fig. 2, cf. L,O and M,P).

Surviving $D 114^{+/-}$mice were apparently normal, suggesting that in these animals the major defects caused by reduction of Dll4 are transient. Subtle defects in the ability of the adult mice to undertake neoangiogenesis have not yet been examined. However, both the male and female mice are fertile, showing that the neovascularization associated with gametogenesis and pregnancy is not impaired. This allowed us to intercross D114 ${ }^{+/-}$mice to examine the homozygous null phenotype. The embryos were collected at E8.5-E10.5, genotyped by PCR of yolk

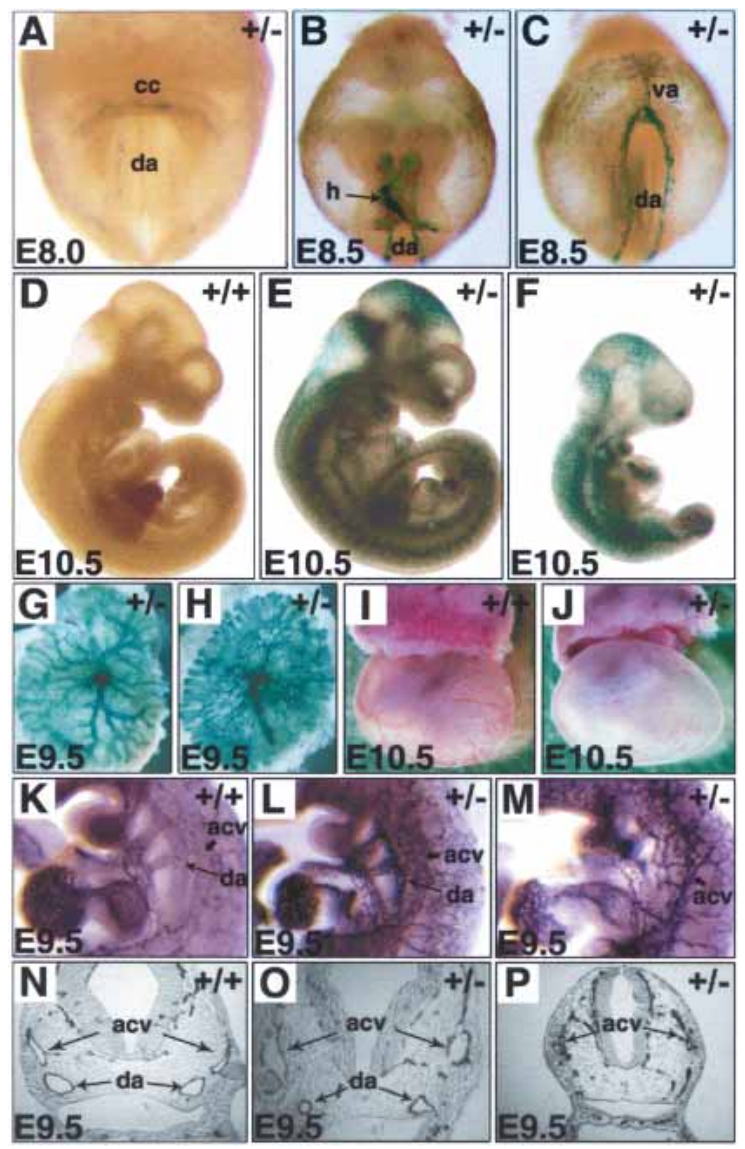

Figure 2. Dll4 haploinsufficiency. $(A-H)$ Whole-mount X-gal staining. $(K-P)$ PECAM immunostaining: whole-mount $(K-M)$ and sections $(N-P) .(I, J)$ Unstained specimens. $(A)$ Dll4 expression at twosomite stage in the cardiac crescent (cc) and dorsal aortae (da) primordia. $(B, C)$ At E8.5, Dll4 expression is observed in all arterial vessels (da, dorsal aortae; va, vitelline arteries) and in the endothelial lining of the heart $(\mathrm{h}) .(D-H)$ Variable penetrance of the hemizygous phenotype: littermate embryos (E10.5, D-F) and arterial vessels of the placenta $(\mathrm{E} 9.5, G, H) .(I, J)$ Morphology of E10.5 yolk sacs. Note the absence of large vitelline vessels and the poor circulation in the $D 114^{+/-}$yolk sac compared with wild-type. $(K-P)$ At E9.5 two types of $D 114^{+/-}$embryos can be found: with reduced dorsal aorta but without defects in the anterior cardinal vein $(L, O)$ and with more severe defects, with a very reduced dorsal aorta, enlarged heart, and the anterior cardinal vein reduced to a disorganized venous plexus $(M, P)$. 
sac DNA, and analyzed by X-gal staining and PECAM immunostaining. Homozygous mutant embryos were found at normal Mendelian frequencies at E9.5 (wildtype, $27.1 \%$; D114 ${ }^{+/}, 47.9 \%$; D114 ${ }^{-/-}, 25.0 \%$; $n=239$ ) but at E10.5 no viable D114 ${ }^{-/-}$embryos were found $(n=48)$. In addition, no Dl14 ${ }^{-/-}$offspring was obtained (wild-type, $\left.62.5 \% ; D 114^{+/-}, 37.5 \% ; n=39\right)$. As expected, RT-PCR analysis demonstrated the complete absence of D114 mRNA in the null embryos (Fig. 1D).

The D114 ${ }^{-/-}$embryos showed more severe and precocious vascular defects than heterozygotes. Mutant embryos were morphologically normal until E8.5 (data not shown), and LacZ expression from the D114 locus was similar in intensity to the heterozygotes. The correct migration and aggregation of the angioblasts occurred to form the dorsal aortae, showing no disruption of the onset of vasculogenesis. However, the dorsal aortae already showed a clear reduction in diameter by E8.75 (Fig. 3A,B). By E9.0 the homozygous null embryos were highly delayed and abnormal, with severe pericardial swelling, and drastically reduced dorsal aortic diameter

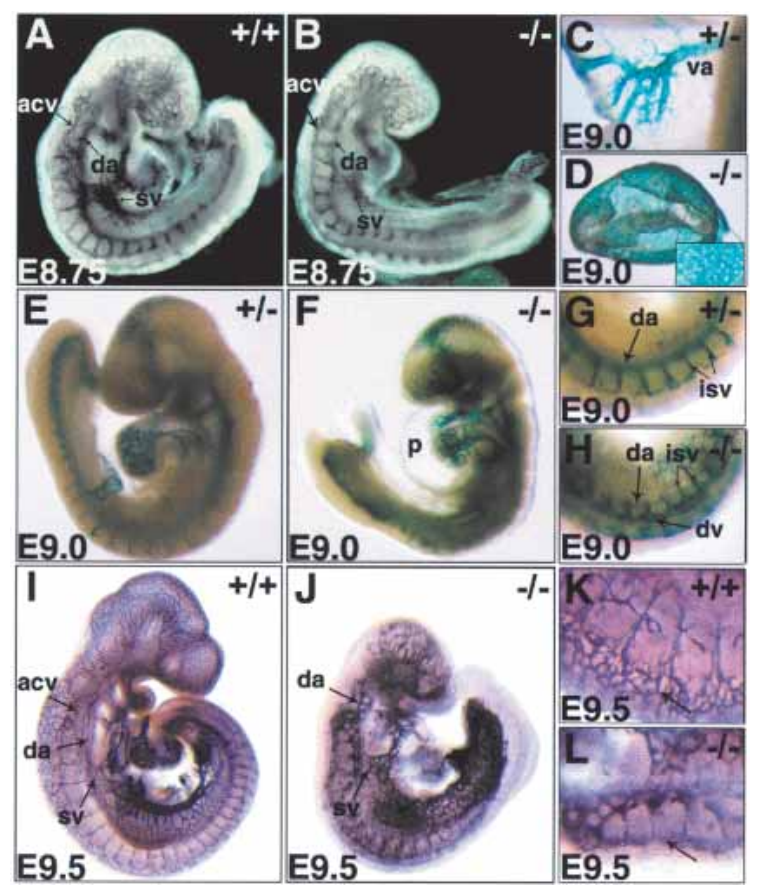

Figure 3. Defective arterial and venous remodeling in $\mathrm{Dll4^{-/- }}$ embryos. Whole-mount PECAM $(A, B, I-L)$ and X-gal staining $(C-H)$ of control and Dll4 ${ }^{-/}$embryos. At E8.75, Dl14 ${ }^{-/-}$embryos display reduced dorsal aorta (da), anterior cardinal vein $(\mathrm{acv})$, and sinus venosus (sv). $(C, D)$ Presence of vitelline arteries (va) in the yolk sac of a E9.0 Dll4 ${ }^{+/-}$embryo contrasts with $D 114^{-/-}$yolk sac vessels, which appear stalled at the primary capillary plexus stage (inset); in Dll4-/embryos the Dll4-lacZreporter expression is observed throughout the yolk sac vessels. $(E-H)$ By E9.0, Dll4 ${ }^{-/}$embryos exhibit growth retardation and arrested heart development with pericardial edema $(\mathrm{p})$; the dorsal aorta appears further reduced, and there is an abnormal accumulation of lacZ-positive cells in the apical portion of the intersomitic vessels (isv) forming an enlarged dorsal vessel (dv). By E9.5, the Dl14 ${ }^{-/-}$embryos are severely retarded with extremely reduced dorsal aortae, a reduced and almost indistinguishable venous structure, sinus venosus, and anterior cardinal vein. $(K, L$; higher magnification of $I, J$, respectively) In the more dorsal region, instead of an intricately branched network between arterial and venous intersomitic vessels, the $D 114^{-/-}$embryos display a single fused vessel that did not undergo angiogenic remodeling. in the anterior region (Fig. 3E-H). Not only were the major arteries abnormal; branching morphogenesis was also affected. D114 ${ }^{-1-}$ embryos showed an abnormal accumulation of $\mathrm{lacZ}^{+}$endothelial cells in the apical portion of the intersomitic vessels and an abnormally dilated dorsal vessel in this region (Fig. 3, cf. G and H).This defect would result in abnormal blood circulation in the embryo, with misdirection from the dorsal aorta to the lateral vessels.

Yolk sac circulation was also highly abnormal. The vitelline artery was drastically reduced, and the yolk sac vascular plexus showed an angiogenic remodeling defect with persistence of the primary capillary bed. Interestingly, whereas in the heterozygous embryos the lacZ reporter was strictly expressed in the arterial (posterior) region of the yolk sac vasculature, in the null embryos, lac $Z$ was expressed in all endothelial cells of the yolk sac plexus (Fig. 3C,D). Although vitelline arteries fail to form, D114 expression is clearly activated in the yolk sac precursors, consistent with it being upstream of the genes that specify artery fate.

By E9.5 these phenotypic traits were accentuated, with more pronounced growth retardation and arterial atrophy, the dorsal aortae being absent or reduced to a rudimentary capillary plexus (Fig. 3I,J). The hearts in these embryos showed reduced atrial and ventricular chambers, and the ventricular trabeculation was markedly reduced (data not shown). The head vasculature consisted of a simple plexus of disorganized and fused vessels (Fig. $3 \mathrm{~J})$. Venous development was also impaired in the null embryos. At E8.75 the anterior cardinal vein already appeared to have a reduced caliber and ectopic branching at some points, and the sinus venosus appeared smaller (Fig. 3A,B). By E9.0 the anterior cardinal vein was further reduced, and by E9.5, a distinct anterior cardinal vein was absent and the embryos showed a very reduced sinus venosus (Fig. 3I,J). Therefore, although the major arteries and veins of the embryo form in the absence of D114, their later development is severely disrupted. As D114 expression is artery-specific, the venous defects are likely secondary to arterial patterning and growth problems.

In zebrafish, Notch signaling has been implicated in the specification of arterial endothelial cells by suppressing the venous cell fate (Lawson et al. 2001, 2002; Zhong et al. 2001). To investigate whether the disruption of vascular development in D114 mutants could be at least partially attributable to abnormal identity of the vascular endothelial cells, we carried out RNA in situ hybridization and immunostaining to determine the expression of arterial and venous markers. In D114 ${ }^{-/-}$embryos with residual intact dorsal aortae, the VEGF receptor, Flk1, was normally expressed in both arteries and veins, and the D114-lacZreporter was expressed in the arteries. However none of the downstream arterial markers studied (EphrinB2, Connexin37, and Connexin40) were expressed in the endothelium (Fig. 4A-F; data not shown). This is consistent with the proposed pathway from zebrafish, where VEGF signaling upstream of Notch signaling promotes arterial cell fate (Lawson et al. 2002). In addition to loss of arterial markers, the venous marker EphB4 was ectopically expressed in the dorsal aortae as well as the cardinal veins (Fig. 4J). In some null embryos, from E9.0, the dorsal aorta fused with the anterior cardinal vein at the level of the sinus venosus (Fig. 4J), consistent with possible loss of separate identity of the two 


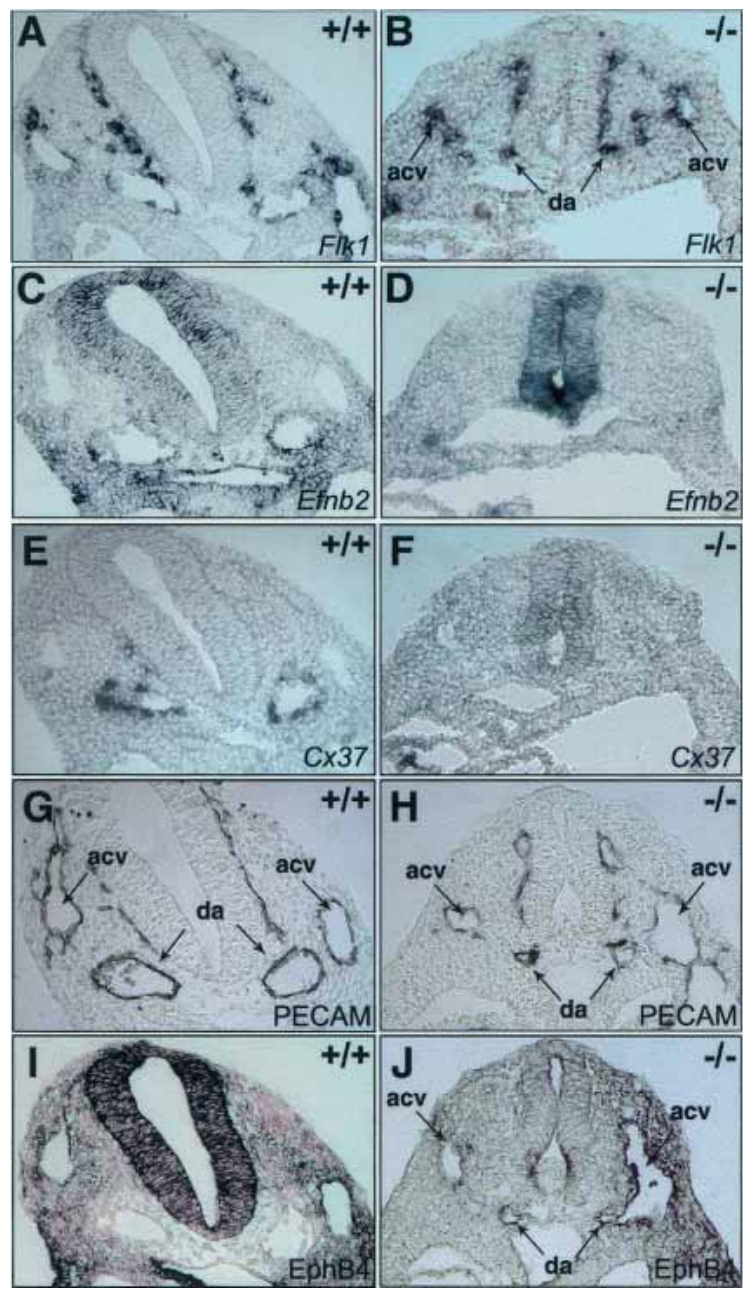

Figure 4. Loss of arterial identity in $D 114^{-/-}$endothelial cells. In situ hybridization $(A-F)$ and immunostaining $(G-J)$ of adjacent cryosections from E9.0 embryos. $(A, B)$ Flk-1 mRNA is present in the endothelial cells of both dorsal aorta (da) and anterior cardinal vein (acv). $(C, F)$ Endothelial cells in Dll4 ${ }^{-/}$embryos fail to express arterial-specific EphrinB2 (Efnb2) and Connexin37 (Cx37) mRNAs. (G-J) The endothelial cells (shown by PECAM immunostaining in $G, H$ ) lining the dorsal aortae in Dll4 ${ }^{-/}$embryos express the venous-specific EphB4 receptor; notice also the fusion between the dorsal aorta and the anterior cardinal vein on the right side of the picture $(J)$.

vessels. These data strongly suggest an involvement of the Notch signaling pathway, mediated through the Dll4 ligand in a cell-autonomous manner, in the establishment of the endothelial arterial cell phenotype in mice. The similarity of the $D 114^{-/-}$phenotype to that of the Notch1/4 double mutants (Krebs et al. 2000) is consistent with this, as is the contrasting effect of endothelialspecific activated Notch expression (Uyttendaele et al. 2001). Loss of arterial vascular identity, in $D 114^{-1-}$ mutants, in turn, could cause angiogenic defects leading to a generalized disruption of the vasculature and embryonic death. However, this loss of arterial endothelial identity is probably not sufficient to explain all the vascular defects observed, such as reduction in aortic caliber and complete absence of arterial organization in the yolk sac. Notch signaling, in addition to regulating the endothelial cell fate, may also regulate the growth of arteries, through the regulation of endothelial cell proliferation and/or the maintenance of a pool of undifferentiated angioblasts.

The strain-dependent haploinsufficiency of D114 was surprising because no other component of the Notch pathway has shown such an effect on vascular development. Indeed, this is the first reported lethal haploinsufficiency for any Notch signalling component in mammals. However, vascular development-related haploinsufficiency has also been reported for the VEGF gene (Carmeliet et al. 1996; Ferrara et al. 1996), which lies upstream of Notch signaling in arterial development (Lawson et al. 2002). This suggests that the development and patterning of the arterial system may be controlled by levels of availability of critical ligands. Interestingly, both VEGF and Dll4 have been shown to be up-regulated by hypoxia (Shweiki et al. 1992; Mailhos et al. 2001), which is one of the environmental factors that can impinge on vascular patterning and growth. Presumably, exquisite sensitivity to ligand levels helps to ensure appropriate vascular responses to changing external environments. Sensitivity of the embryonic vasculature to Dll4 levels raises the possibility that Dll4 might be a good target for intervention in adult neovascularization.

\section{Materials and methods}

Generation of mice carrying a germ-line mutation of Dll4

Mouse D114 genomic clones were isolated from a 129/Sv genomic library and characterized using standard protocols. In the targeting vector, a 2.0-kilobase $(\mathrm{kb})$ DNA fragment encompassing the start codon and the first three exons of the D114-coding sequence was deleted and substituted by a lacZ and PGK-neo cassette, flanked by 1.5-kb 5' and 5-kb 3' homologous regions (Fig. 1A). This vector was linearized with NotI and electroporated into R1 ES cells. Correctly targeted clones were identified by PCR assays and confirmed by Southern blotting (Fig. 1B). Chimeric mice were generated by morula aggregation (Nagy et al. 1993), and males were crossed with ICR females.

Screening for germ-line transmission and genotyping was performed by PCR analysis of tail biopsy DNA (Fig. 1C) using the following primers: P1， 5'-GGGGAATCAGCTTTTCAGGAA-3'; P2， 5'-CGAACTCCTG CAGCCGCAGCT-3'; P3, 5'-ACGACGTTGTAATACGAC-3' (Fig. 1A).

Generation of $\mathrm{Dll4}^{+/}$ES-derived embryos

$D 114^{-/-}$ES cell lines were used in aggregations with EGFP-expressing tetraploid embryos as described (Hadjantonakis et al. 1998). Two-cell diploid embryos were fused to become tetraploid one-cell embryos, cultured to the four-cell stage, and aggregated with ES cells. Composite embryos were cultured overnight and then transferred to pseudopregnant recipients.

In situ hybridization, immunohistochemistry, and lacZ staining Embryonic age was initially determined by the date of the formation of the copulation plug and confirmed by number of somites. Whole-mount immunohistochemistry and lac $Z$ staining were carried out by standard techniques (Hogan et al. 1994). Antibodies were from Pharmingen (PECAM) and R\&D Systems (EphB4). Digoxigenin-labeled RNA probes were transcribed from linearized templates, and in situ hybridization of cryosections was carried out as described (Henrique et al. 1997). Probe sizes were as follows: EphrinB2, 700 bp; Flk1, 800 bp; Connexin37, 978 bp; Connexin40, $1000 \mathrm{bp}$.

RT-PCR analysis

Individual yolk sacs and embryos from $D 114^{+/-}$intercrosses were dissected and used to isolate total RNA from which first-strand cDNA was synthesized using a SuperScript Preamplification System kit (GIBCOBRL). First-strand cDNA $(0.1 \mu \mathrm{g})$ was used for PCR with specific primers for D114 (forward, 5'-AGCTGGAAGTGGACTGTGGT-3'; reverse, 5 ' TAGAGTCCCTGGGAGAGCAA- $3^{\prime}$ ) and, as a control, $\beta$-actin (forward, 5'-ACCGTGAAAAGATGACCCAG-3'; reverse, 5'-GCTGTGGTGGT 
GAAGCTGTA-3'). PCR products were visualized by ethidium bromide staining (Fig. 1D).

\section{Acknowledgments}

We thank Joachim Gossler for vectors, David Anderson and Donghun Shin for riboprobes, Malgosia Kownacka for advice and technical help on the ES cell work, Ken Harpal for histological sections, and Lois Byers for generating chimeras. These studies were partially supported by grants from the Portuguese Research Council (F.C.T.) to A.D. and D.H. and a Terry Fox grant from the National Cancer Institute of Canada to J.R. J.R. is a Distinguished Investigator of the Canadian Institutes for Health Research.

\section{References}

Carmeliet, P., Ferreira, V., Breier, G., Pollefeyt, S., Kieckens, L., Gertsenstein, M., Fahrig, M., Vandenhoeck, A., Harpal, K., Eberhardt, et al. 1996. Abnormal blood vessel development and lethality in embryos lacking a single VEGF allele. Nature 380: 435-439.

Ferrara, N., Carver-Moore, K., Chen, H., Dowd, M., Lu, L., O'Shea, K.S. Powell-Braxton, L., Hillan, K.J., and Moore, M.W. 1996. Heterozygous embryonic lethality induced by targeted inactivation of the VEGF gene. Nature 380: 439-442.

Fischer, A., Schumacher, N., Maier, M., Sendtner, M., and Gessler, M. 2004. The Notch target genes Hey1 and Hey2 are required for embryonic vascular development. Genes \& Dev. 18: 901-911.

Hadjantonakis, A.K., Gertsenstein, M., Ikawa, M., Okabe, M., and Nagy, A. 1998. Generating green fluorescent mice by germline transmission of green fluorescent ES cells. Mech. Dev. 76: 79-90.

Henrique, D., Hirsinger, E., Adam, J., LeRoux, I., Pourquie, O., IshHorowicz, D., and Lewis, J. 1997. Maintenance of neuroepithelial progenitor cells by Delta-Notch signalling in the embryonic chick retina. Curr. Biol. 13: 661-670.

Hogan, B., Beddington, R., Constantini, F., and Lacy, E. 1994. Manipulating the mouse embryo. A laboratory manual. Cold Spring Harbor Laboratory Press, Cold Spring Harbor, NY.

Krebs, L.T., Xue, Y., Norton, C.R., Shutter, J.R., Maguire, M., Sundberg, J.P., Gallahan, D., Closson, V., Kitajewski, J., Callahan, R., et al. 2000. Notch signaling is essential for vascular morphogenesis in mice. Genes \& Dev. 14: 1343-1352.

Lawson, N.D., Scheer, N., Pham, V.N., Kim, C.H., Chitnis, A.B., Campos-Ortega, J.A., and Weinstein, B.M. 2001. Notch signaling is required for arterial-venous differentiation during embryonic vascular development. Development 128: 3675-3683.

Lawson, N.D., Vogel, A.M., and Weinstein, B.M. 2002. sonic hedgehog and vascular endothelial growth factor act upstream of the Notch pathway during arterial endothelial differentiation. Dev. Cell 3: 127136.

Mailhos, C., Modlich, U., Lewis, J., Harris, A., Bicknell, R., and IshHorowicz, D. 2001. Delta4, an endothelial specific notch ligand expressed at sites of physiological and tumor angiogenesis. Differentiation 69: 135-144.

Nagy, A., Rossant, J., Nagy, R., Abramow-Newerly, W., and Roder, J.C. 1993. Derivation of completely cell culture-derived mice from earlypassage embryonic stem cells. Proc. Nat1. Acad. Sci. 90: 8424-8428.

Shawber, C.J. and Kitajewski, J. 2004. Notch function in the vasculature: Insights from zebrafish, mouse and man. Bioessays 26: 225-234.

Shutter, J.R., Scully, S., Fan, W., Richards, W.G., Kitajewski, J., Deblandre, G.A., Kintner, C.R., and Stark, K.L. 2000. Dll4, a novel Notch ligand expressed in arterial endothelium. Genes \& Dev. 14: 13131318.

Shweiki, D., Itin, A., Soffer, D., and Keshet, E. 1992. Vascular endothelial growth factor induced by hypoxia may mediate hypoxia-initiated angiogenesis. Nature 359: 843-845.

Uyttendaele, H., Ho, J., Rossant, J., and Kitajewski, J. 2001. Vascular patterning defects associated with expression of activated Notch4 in embryonic endothelium. Proc. Natl. Acad. Sci. 98: 5643-5648.

Villa, N., Walker, L., Lindsell, C.E., Gasson, J., Iruela-Arispe, M.L., and Weinmaster, G. 2001. Vascular expression of Notch pathway receptors and ligands is restricted to arterial vessels. Mech. Dev. 108: 161164.
Zhong, T.P., Childs, S., Leu, J.P., and Fishman, M.C. 2001. Gridlock signalling pathway fashions the first embryonic artery. Nature 414: $216-220$. 


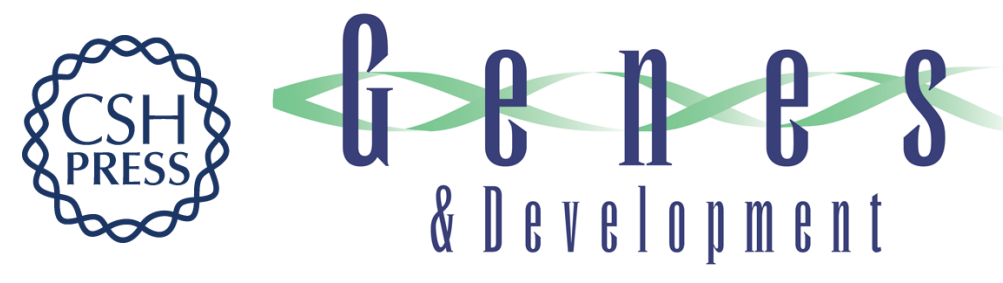

\section{Dosage-sensitive requirement for mouse DIl4 in artery development}

António Duarte, Masanori Hirashima, Rui Benedito, et al.

Genes Dev. 2004, 18:

Access the most recent version at doi:10.1101/gad.1239004

References This article cites 15 articles, 6 of which can be accessed free at: http://genesdev.cshlp.org/content/18/20/2474.full.html\#ref-list-1

License

Email Alerting Receive free email alerts when new articles cite this article - sign up in the box at the top Service right corner of the article or click here.

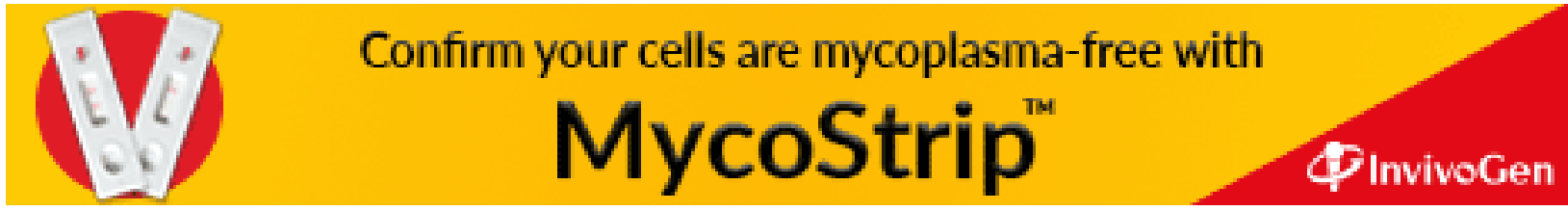

